\title{
$E$ region neutral winds in the postmidnight diffuse aurora during the Atmospheric Response in Aurora 1 rocket campaign
}

\author{
D. G. Brinkman, R. L. Walterscheid, L. R. Lyons, D. C. Kayser,1 \\ and A. B. Christensen \\ Space and Environment Technology Center, The Aerospace Corporation, Los Angeles, California
}

J. R. Sharber and R. A. Frahm

Department of Space Sciences, Southwest Research Institute, San Antonio, Texas

\section{F. Larsen}

Department of Physics and Astronomy, Clemson University, Clemson, South Carolina

\begin{abstract}
Measured $E$ region neutral winds from the Atmospheric Response in Aurora (ARIA 1) rocket campaign are compared with winds predicted by a high-resolution nonhydrostatic dynamical thermosphere model. The ARIA 1 rockets were launched into the postmidnight diffuse aurora during the recovery phase of a substorm. Simulations have shown that electrodynamical coupling between the auroral ionosphere and the thermosphere was expected to be strong during active diffuse auroral conditions (Walterscheid and Lyons, 1989). This is the first time that simulations using the time history of detailed specifications of the magnitude and latitudinal variation of the auroral forcing based on measurements have been compared to simultaneous wind measurements. Model inputs included electron densities derived from ground-based airglow measurements, precipitating electron fluxes measured by the rocket, electron densities measured on the rocket, electric fields derived from magnetometer and satellite ion drift measurements, and large-scale background winds from a thermospheric general circulation model. Our model predicted a strong jet of eastward winds at $E$ region heights. A comparison between model predicted and observed winds showed modest agreement. Above $135 \mathrm{~km}$ the model predicted zonal winds with the correct sense, the correct profile shape, and the correct altitude of the peak wind. However, it overpredicted the magnitude of the eastward winds by more than a factor or 2 . For the meridional winds the model predicted the general sense of the winds but was unable to predict the structure or strength of the winds seen in the observations. Uncertainties in the magnitude and latitudinal structure of the electric field and in the magnitude of the background winds are the most likely sources of error contributing to the differences between model and observed winds. Between 110 and $135 \mathrm{~km}$ the agreement between the model and observations was poor because of a large unmodeled jetlike feature in the observed winds $\left(140 \mathrm{~m} \mathrm{~s}^{-1}\right)$.

Agreement between the present simulation and the earlier simulations of Walterscheid and Lyons (1989) is favorable, although the winds in the present simulation are considerably weaker for particle precipitation of similar characteristic energy and flux. The reasons for the difference were the smaller latitudinal extent of the model diffuse aurora and the weaker electric fields in our simulation. We have shown that the enhanced electron densities and electric fields associated with the postmidnight diffuse aurora provide the potential for a rapid acceleration of the zonal winds as shown by Walterscheid and Lyons (1989). However, the modeled response to the large-scale electric field is too great. This suggests that the assimilated mapping of ionospheric electrodynamics (AMIE) electric field is also too large. The actual electric field is most likely reduced locally in regions of enhanced ionization and conductivity within the diffuse aurora. In addition, we have shown that the "exotic" jetlike wind feature between 110 and $135 \mathrm{~km}$ is not aurorally forced. However, it may be the result of an enhancement of the Hall drag relative to the Coriolis force that modifies the geostrophic balance with the large-scale pressure gradient.
\end{abstract}

\footnotetext{
${ }^{1}$ Deceased, March 26, 1993.

Copyright 1995 by the American Geophysical Union. 


\section{Introduction}

The postmidnight diffuse aurora is a region of strong electrodynamic interaction between the ionosphere and the thermosphere. Enhanced ionization due to increased particle precipitation, strong electric fields which are not apt to be as strongly reduced as in discrete arcs [Evans et al., 1977], and the stability of the diffuse aurora [Akasofu, 1974; Whalen, 1983 ] may combine to produce a strong acceleration of the $E$ region neutral winds through the ion drag mechanism. [Killeen et al., 1984, 1986; Larsen and Mikkelsen, 1983; Roble et al., 1982, 1984; Walterscheid and Boucher, 1984; Lyons and Walterscheid, 1985; Walterscheid and Lyons, 1989.]

In an earlier study, Lyons and Walterscheid [1985] used a high-resolution two-dimensional thermospheric model to examine the zonal winds generated by ion drag produced by an idealized representation of an enhanced ionosphere due to electron precipitation within the diffuse aurora. Model results showed that auroral forcing could produce a strong $E$ region wind jet with large horizontal shears that were found to be unstable with respect to the Kelvin-Helmholtz instability. More recently, Walterscheid and Lyons [1989] used observations of electron particle precipitation [Lyons and Fennell, 1986] to better characterize the electron density at $E$ region heights. They examined various latitudinal structures for both hard and soft spectra and included the effects of large-scale cross-auroral winds. Their results also predicted a strong zonal wind jet and showed that the width of the aurora and the energy spectra of the particle precipitation can directly affect the magnitude and latitudinal extent of this zonal jet. In addition, they showed that strong cross-auroral winds reduced the magnitude of the zonal jet by limiting the time an air parcel was subject to auroral forcing.

The search for strong $E$ region winds as predicted by Lyons and Walterscheid [1985] and Walterscheid and Lyons [1989] (hereinafter referred to as WL) was a major motivation for the Atmospheric Response in Aurora (ARIA) rocket program [Anderson et al., 1995]. The ARIA objectives included inferring the forces acting on neutrals in the postmidnight diffuse aurora and modelling the atmospheric response to these forces. The fully instrumented ARIA 1 rocket was launched into the recovery phase of a moderate substorm. It was preceded by a chemical release rocket that was used to obtain a height profile of the horizontal winds on the downleg of its trajectory.

In this paper we apply the WL model to the time period of the ARIA 1 substorm and compare the modeled winds at the time and location of the chemical release to those measured from the release. We base the spatial and temporal variations of enhanced $E$ region electron densities and electric fields in the diffuse aurora upon observations. The variation of electron density was obtained from airglow measurements from a ground-based photometer pointing up a magnetic field line, an all-sky camera, and a ground-based meridian scanning photometer (MSP), along with particle and electron density measurements from the ARIA 1 rocket flight. The variation of electric fields was determined from coordinated groundbased magnetometer measurements and ion drift measurements from a Defense Meteorological Satellite Program (DMSP) satellite. In addition, background winds obtained from a sophisticated three-dimensional thermospheric gen- eral circulation model were used as input to our highresolution two-dimensional simulation of the neutral response to auroral forcing.

The rest of this paper is organized as follows: section 2 describes the model, section 3 describes the inputs used in the simulation, section 4 describes the model results, section 5 discusses the comparison of our model results to the ARIA observations and previous simulations, and finally section 6 summarizes the major conclusions of this study.

\section{Model}

We used the two-dimensional time-dependent thermospheric model described by Walterscheid et al. [1985] and WL. It solves the nonhydrostatic, nonlinear, flux form of the equations of motion for a plane rotating atmosphere. The model employs a splitting method for the time-differencing scheme in which the terms describing fast moving acoustic waves are solved implicitly, and the remaining terms are solved explicitly using a Lax-Wendroff scheme.

The model domain was centered at $65^{\circ} \mathrm{N}$ magnetic latitude (hereinafter, when we say latitude, we are referring to magnetic latitude unless specified otherwise) and oriented so that the cross-auroral direction was aligned with a magnetic meridian. The domain extends $\pm 2000 \mathrm{~km}$ horizontally and from 50 to $355 \mathrm{~km}$ vertically. The region of interest, the central $400 \mathrm{~km}$ of the horizontal domain, has a uniform grid spacing of $40 \mathrm{~km}$ horizontally, while vertically it has a constant grid spacing of $2.5 \mathrm{~km}$ between 100 and $250 \mathrm{~km}$. Outside of this region, the spacing varies to move the boundaries far enough away from the region of interest that the boundary conditions do not influence the model results. In addition, boundary conditions are used that prevent fast moving waves from reflecting back into the center of the model domain. Rayleigh sponge layers between 50 and 100 $\mathrm{km}$ and between 250 and $355 \mathrm{~km}$ prevent vertical reflections, while Perkey and Kreitzherg [1976] absorbing regions prevent reflections from the lateral boundaries.

The model is a one (mean) gas model. However, composition-dependent quantities such as the gas constant and specific heats are allowed to vary with height. In addition, ion drag, Joule heating, and particle heating are described in terms of electric fields and ion density as in the work by Walterscheid et al. [1985]. Ion drag is prescribed as in the work by Straus and Schulz [1976], while Joule heating is prescribed as in the work by St-Maurice and Shunk [1981]. Particle heating is formulated as in the works by Richmond and Matsushita [1975] and Hays et al. [1973].

\section{Simulation Inputs}

In this study we simulated the $E$ region neutral wind response to the postmidnight diffuse aurora for the period (1000-1415 UT) leading up to and including the ARIA rocket flights on March 3, 1992 [Anderson et al., 1995]. The time history of the aurora for this period can be seen in Figure 1. The figure shows characteristic electron energy in kiloelectron volts, determined by using the optical brightness ratios $I(630.0 \mathrm{~nm}) / I(427.8 \mathrm{~nm})$ and $I(844.6 \mathrm{~nm}) / I(427.8 \mathrm{~nm})$ as by Hecht et al. [1989], and the brightness of auroral $\mathrm{N}_{2}^{+}(427.8$ $\mathrm{nm}$ ) in kilorayleighs, measured by a ground-based photometer at Poker Flat, Alaska, pointing in the magnetic zenith. We have divided the period into four intervals (1000-1130, 


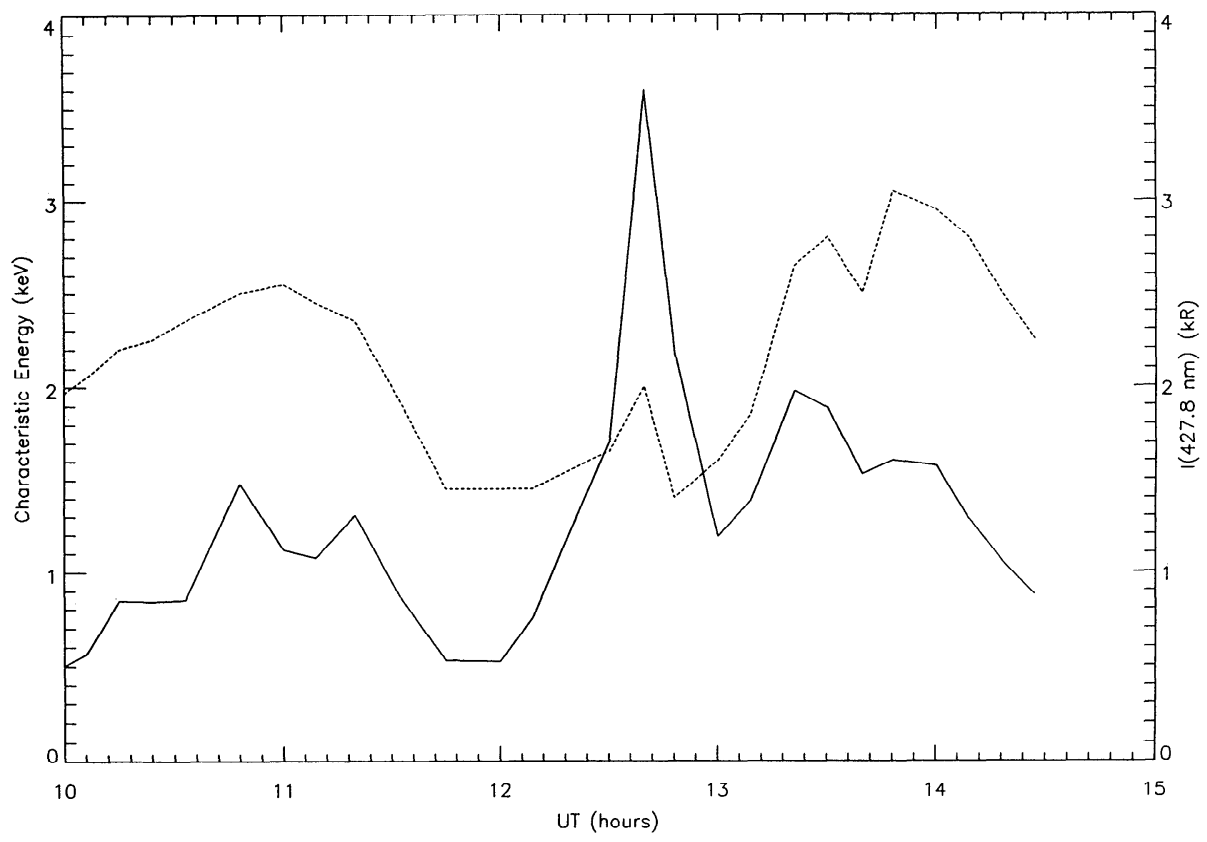

Figure 1. Characteristic energy in keV (solid line) and brightness of 427.8-nm airglow emissions in kilorayleighs (dotted line) over Poker Flat, Arkansas measured by the field-aligned photometers from 1000 UT to 1500 UT (from [Anderson et al., 1995]).

$1130-1210,1210-1320$, and 1320-1410 UT) for carrying out our model simulations. For each time period we need to specify an electron density profile, the latitudinal variation of electron density, the magnitude and latitudinal variation of the electric field, and a background wind profile. The following sections describe how we used the measurements from the ARIA rockets and coordinated ground-based measurements to specify these inputs.

\subsection{Electron Density}

For each of the simulation periods an enhanced $E$ region electron density profile was specified. For simulation periods 1-3 we first estimated a time-averaged characteristic electron energy and a time-averaged total energy flux incident on the atmosphere for each period. The characteristic energy was obtained from the data shown in Figure 1, as described earlier. The total energy flux was inferred directly from the 427.8-nm auroral brightness measurements shown in Figure 1 normalized so that the flux was consistent with the precipitating electron flux measured on the rocket [see Anderson et al., 1995]. The energy flux and characteristic energy were then used as inputs to the Strickland electron transport code [Strickland et al., 1976, 1983; Daniell and Strickland, 1986] to provide the enhancement in the ionospheric electron density profile above Poker Flat. Figure 2a shows the electron density profiles calculated this way for the first three periods. The solid line is a fit [Lindzen, 1970] to the enhanced electron density profile for period 1 . This profile has a peak density of $2.1 \times 10^{11} \mathrm{~m}^{-3}$ at an altitude of $111 \mathrm{~km}$ and corresponds to a characteristic energy of $2.25 \mathrm{keV}$ and a flux of $4.3 \mathrm{~mW} \mathrm{~m}^{-2}$. The dashed-dotted line is the fit for period 2 with a peak density of $1.95 \times 10^{11} \mathrm{~m}^{-3}$ at an altitude between 115 and $120 \mathrm{~km}$. This profile corresponds to a characteristic energy of $1.5 \mathrm{keV}$ and a flux of $3.2 \mathrm{~mW} \mathrm{~m}^{-2}$. The dashed line is the fit for period 3 and exhibits a peak density of $3.38 \times 10^{11} \mathrm{~m}^{-3}$ at an altitude between 115 and $120 \mathrm{~km}$. This corresponds to a characteristic energy of $1.5 \mathrm{keV}$ and a flux of $8.6 \mathrm{~mW} \mathrm{~m}^{-2}$. The dotted line represents the background electron density profile from the Chiu ionosphere model [Chiu, 1975] run for the ARIA period. This profile is added to the profiles of the electron density enhancement discussed above to obtain the total electron density used in the simulations.

The electron density profile for simulation period 4 was obtained in a different manner. Figure 6 of Anderson et al. [1995], shows that there were two distinct particle precipitation regimes within the diffuse aurora during this period. There is an intense center region within $\pm 55 \mathrm{~km}$ of the location of peak particle precipitation and lower intensity wings outside of this region. We use the electron density measured by the Langmuir probe during the ARIA flight [Anderson et al., 1995] to describe the electron density variation in the two regimes. The upleg measurements approximately $25-50 \mathrm{~km}$ north of Poker Flat were used to characterize the center region, while the downleg measurements (approximately $210 \mathrm{~km}$ north of Poker Flat) were used to characterize the wings of the aurora. Both the upleg and downleg electron density profiles were normalized to be consistent with the precipitating electron flux measured on the rocket at $120 \mathrm{~km}$ on the upleg of the flight [Anderson et $a l ., 1995]$. In Figure $2 \mathrm{~b}$ the solid line represents the fit to the upleg (center) profile, while the dashed line represents the fit to the downleg (wings) profile. The upleg profile exhibits a peak density of $4 \times 10^{11} \mathrm{~m}^{-3}$ at an altitude of $107 \mathrm{~km}$. The downleg profile exhibits a peak density of $6 \times 10^{10} \mathrm{~m}^{-3}$ at an altitude of $115 \mathrm{~km}$.

\subsection{Latitudinal Variation}

The latitudinal variation of the enhanced $E$ region electron density was specified by prescribing a latitudinal scaling function for simulation periods $1-3$ and two separate functions for simulation period 4 (one for the center region and one for the wings). Each scaling function produces a scale 


\section{Electron Density 1000 - 1320 UT}

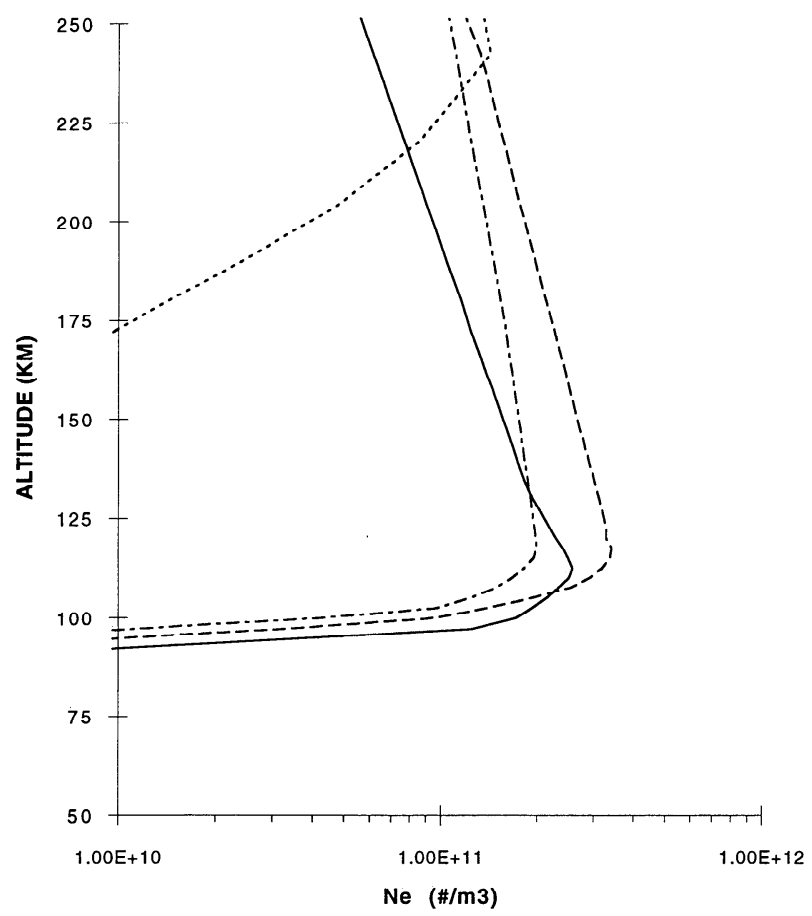

Figure 2a. Electron density profiles used in the first three simulation periods extending from 1000 UT until $1320 \mathrm{UT}$. The profile for the first period $(1000-1130$ UT) is shown by the solid line. The profile for the second period (1130-1210 UT) is shown by the dashed-dotted line. The profile for the third period (1210-1320 UT) is shown by the dashed line. The dotted line represents the background electron density profile from the Chiu ionosphere model run for the ARIA time period.

factor between 0 and 1 as a function of latitude and is used to scale the enhanced electron density profiles calculated in section 3.1, which apply at one latitude, so that they can be applied at other latitudes. The latitudinal variation of the scaling function was based on the latitudinal variation of either auroral brightness or particle precipitation flux.

For simulation periods 1-3 the latitudinal scaling functions were based on the latitudinal variation of 427.8-nm auroral measurements using a MSP and an all-sky camera, both located at Poker Flat [Anderson et al., 1995]. The scale factor at each latitude was obtained by taking the square root of the brightness at that latitude and normalizing to the square root of the peak brightness. Figure 3 a shows scale factor as a function of latitude for period 1 (solid line), period 2 (dashed-dotted line), and period 3 (dashed line). For simulation periods $1-3$ the scaling functions peak near $65^{\circ} \mathrm{N}$ latitude and decrease to a value of 0.5 about $\pm 3^{\circ}$ latitude away from the peak. Outside of this region, the scaling functions level off to a constant value with increasing distance from $65^{\circ} \mathrm{N}$ latitude. The values of the scaling functions outside of $65^{\circ} \mathrm{N} \pm 3^{\circ}$ latitude were based on brightness measurements that were made at zenith angles greater than $70^{\circ}$ and may be artificially high due to scattering [Anderson et al., 1995]. This may affect the latitudinal extent of the aurora in our model simulations (wider than actual) but should not affect the results within $\pm 3^{\circ}$ latitude of Poker Flat, our region of interest.

The latitudinal variation for the scaling function used for the center region of the aurora in simulation period 4 was based on the precipitating electron flux measurements shown in Figure 6 of Anderson et al. [1995]. The scale factor at each latitude was obtained by taking the square root of the integrated particle precipitation flux at the latitude and then normalizing it to the square root of the peak particle flux. The solid line in Figure $3 b$ is the scaling function that represents this variation and is used only within $\pm 55 \mathrm{~km}$ of the peak. The peak of the scaling function is located near $65^{\circ} \mathrm{N}$ latitude and decreases rapidly (more rapidly than for the previous three periods) away from the peak. The scaling function for describing the latitudinal variation of the wings of the aurora during simulation period 4 was also based on the precipitating electron flux data and is shown as the dashed line in Figure $3 \mathrm{~b}$. The scale factor at each latitude was obtained by taking the square root of the integrated particle flux at that latitude and then normalizing it to the square root of the peak particle flux, which for the purposes of normalization must be extrapolated back to a peak at $65^{\circ} \mathrm{N}$ latitude. The scaling function exhibits a much slower decrease as a function of distance than the scaling function for the center region and is used only at distances greater than $\pm 55 \mathrm{~km}$ away from the peak.

Electron Density 1320 - 1410 UT

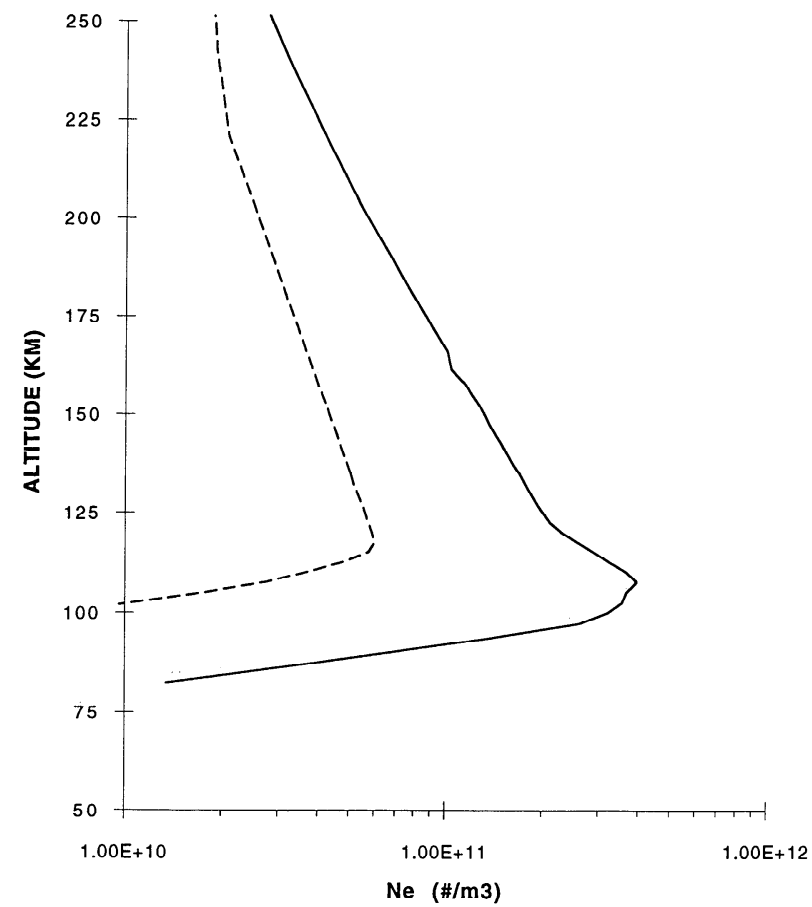

Figure 2b. Electron density profiles measured by the ARIA 1 Langmuir probe on the upleg (solid line) and the downleg (dashed line) of the rocket flight. The upleg and downleg profiles were used to characterize the "center" and the "wings" of the aurora during the fourth simulation period, respectively. 


\section{LATITUDE STRUCTURE 10:00-13:20 UT}

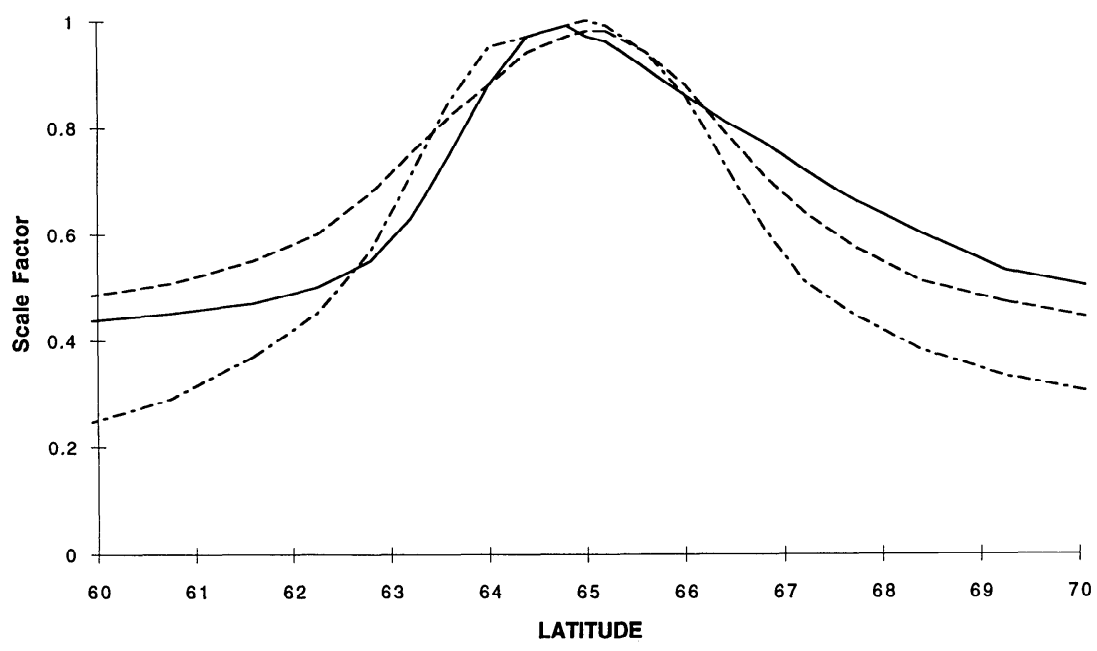

Figure 3a. Latitudinal scaling functions used for the first three simulation periods (solid line, 1000-1130 UT; dashed-dotted line, 1130-1210 UT; and dashed line, 1210-1320 UT).

\subsection{Electric Fields}

The magnitude and latitudinal variation of the electric field was determined from coordinated ground-based magnetometer measurements and ion drift measurements from the DMSP satellite. These measurements were provided as input to the assimilated mapping of ionospheric electrodynamics (AMIE) process [Richmond and Kamide, 1988; Richmond et al., 1988]. AMIE is a data assimilation technique which uses all available data to obtain the best representation, in a least squarcs scnsc, of the clcctric ficld pattcrn. Rcsults for the period of the ARIA 1 campaign are discussed by M. F. Larsen et al. (The ARIA experiment: Observations of $E$ and $F$ region neutral winds in a region of postmidnight diffuse aurora, submitted to Journal of Geophysical Research, 1994 (hereinafter referred to as Larsen et al., submitted manuscript, 1994)) and Anderson et al. [1995]. The AMIE run provided both magnetic north-south and east-west electric field values approximately every $1.7^{\circ}$ for the entire polar cap and auroral region for half-hour intervals starting at $1000 \mathrm{UT}$ and running through $1430 \mathrm{UT}$. In this simulation only the north-south component (positive northward) was used because it was stronger by more than an order of magnitude than the east-west electric field. Figure 4 shows the magnitude and latitudinal variation of the electric fields from $60^{\circ}$ to $70^{\circ} \mathrm{N}$ magnetic latitude, averaged in time for the four different time periods of this simulation. Figure 4 shows that the clectric ficld during these periods has a relatively broad shape in latitude with a peak between $66^{\circ}$ and $67^{\circ} \mathrm{N}$ magnetic latitude. The peak value increases in magnitude from $-3 \mathrm{mV}$ $\mathrm{m}^{-1}$ during period 1 (dashed-dotted line) to $-12 \mathrm{mV} \mathrm{m}^{-1}$ during period 2 (dotted line) to $-21 \mathrm{mV} \mathrm{m}^{-1}$ during period 3 (dashed line). For period 4 (solid line) the electric field values also were averaged at the given latitudes. During this period the electric field exhibits a relatively sharp peak of $-34 \mathrm{mV}$

\section{LATITUDE STRUCTURE 13:20-14:10 UT}

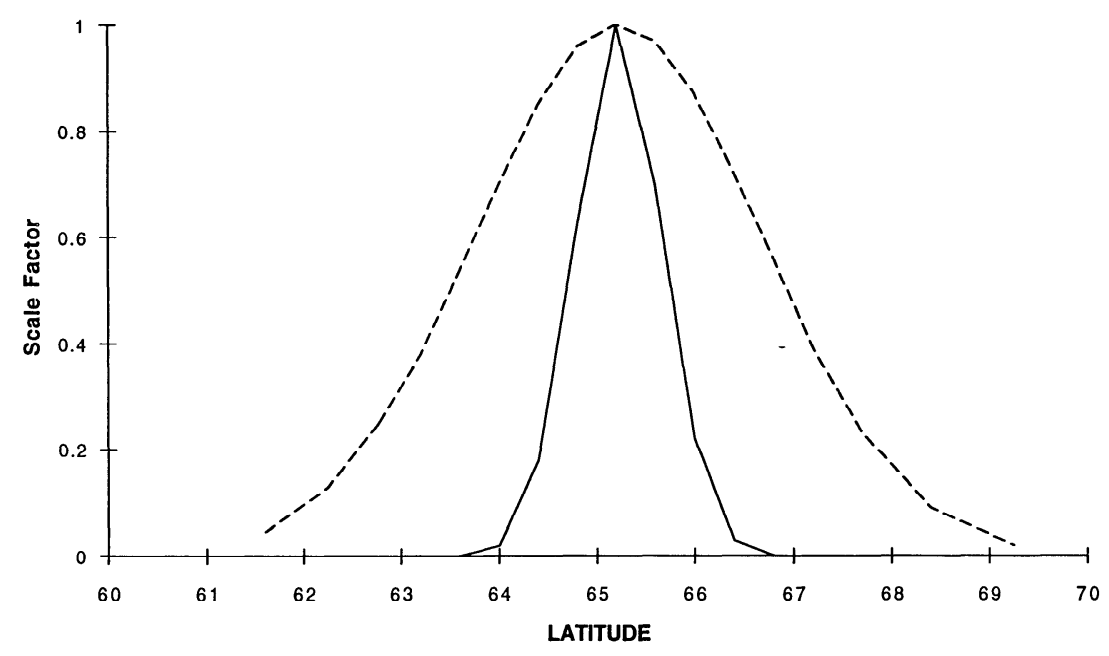

Figure 3b. Latitudinal scaling functions for the center of the aurora (solid line) and for the wings of the aurora (dashed line) during the fourth simulation period. 
E FIELD

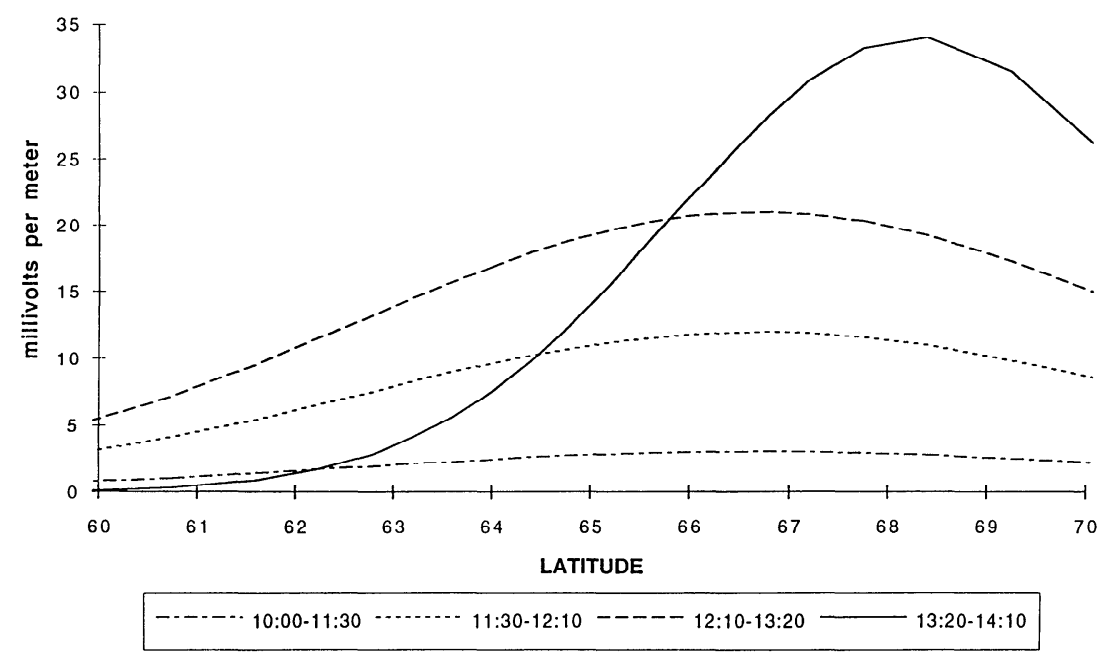

Figure 4. Latitudinal variation of the southward electric field (millivolts per meter) obtained from the assimilated mapping of electrodynamics model for four time intervals between 1000 and 1410 UT (dashed-dotted line, 1000-1130 UT; dotted line, 1130-1210; dashed line, 1210-1320 UT; and solid line 1320-1410 UT).

$\mathrm{m}^{-1}$ and is shifted poleward from its location during the first three periods to $68.3^{\circ} \mathrm{N}$ magnetic latitude.

\subsection{Background Winds}

WL showed that cross-auroral winds can have a significant influence on the acceleration of the thermosphere by ion drag because cross-auroral winds driven by solar heating, and Joule heating due to large-scale convection electric fields limit the amount of time parcels of air spend in the region of strong ion drag acceleration. The WL model does not simulate these large-scale meridional (cross-auroral) winds or the large-scale zonal (along-auroral) winds driven by similar processes. Therefore we accounted for these effects by incorporating the large-scale winds produced by the Danish Meteorological Institute spectral global circulation model (STGCM) into the background state [Mikkelsen and Larsen, 1991]. The STGCM was run starting 8 days prior to the period of interest, with the convection pattern based on interplanetary magnetic field data. Auroral ionization was based on $K_{p}$, therefore some influence of the aurora will be present in the STGCM winds. However, $K_{p}$ is a global index with a 3-hour time resolution and localized features, like the diffuse aurora studied here, are not well captured by the index. In addition, the effective horizontal resolution of the STGCM $(417 \mathrm{~km})$ is too coarse to resolve the intense portions of the diffuse aurora. Hence the influence of the auroral ionization on STGCM winds should be small and spread around at high latitudes. Tides were included on the basis of the work of Forbes and Vial [1990].

The WL model also does not allow for a time-dependent specification of the large-scale winds. Hence we used the time-averaged winds from 1200 to 1400 UT as representative of the period for which the auroral forcing was strongest. The STGCM winds were slower for the period from 1000 to $1200 \mathrm{UT}$, but the auroral forcing was also weak. Hence the difference on the final model results of using the 1200-1400 UT time-averaged winds instead of time-averaged winds from 1000 to 1400 UT should be small. In addition, the winds have been spatially averaged around the ARIA 1 ground track and have been rotated into magnetic coordinates. Figure 5 shows the zonal (solid line) and the meridional (dashed-dotted line) components of the wind averaged over the period from 1200 to $1400 \mathrm{UT}$. The zonal wind $U$ profile (solid line) shows westward winds up to $10 \mathrm{~m} \mathrm{~s}^{-1}$ below 110 $\mathrm{km}$ and peak eastward winds of $27 \mathrm{~m} \mathrm{~s}^{-1}$ between 110 and $160 \mathrm{~km}$. Above $160 \mathrm{~km}$ the winds turn westward again and continue to increase in speed to $27 \mathrm{~m} \mathrm{~s}^{-1}$ near $240 \mathrm{~km}$. The meridional wind $V$ profile (dashed-dotted line) shows weak southward winds of $8 \mathrm{~m} \mathrm{~s}^{-1}$ below $100 \mathrm{~km}$ and peak northward winds of $40 \mathrm{~m} \mathrm{~s}^{-1}$ between 100 and $130 \mathrm{~km}$. Above $130 \mathrm{~km}$ the winds turn southward again and increase in speed to over $120 \mathrm{~m} \mathrm{~s}^{-1}$ at $240 \mathrm{~km}$.

\section{Results}

As described earlier, the simulation was run in four segments, each with a different set of forcing parameters. To prevent the generation of spurious disturbances as the forcing changes, we started each segment with the same forcing as at the end of the previous segment (for the first segment we started with zero forcing) and turned on the new forcing as we turned off the old forcing over a 10 -min period. Figure 6 a shows the perturbation zonal winds after the completion of the simulation. The results reflect just the response to the auroral forcing; the average STGCM winds have been subtracted. Figure 6a shows a broad region of eastward winds extending over $1200 \mathrm{~km}$ which has a peak speed of $175 \mathrm{~m} \mathrm{~s}^{-1}$ between 140 and $160 \mathrm{~km}$ altitudes at the center of the model domain. Below $110 \mathrm{~km}$ the winds become weakly westward. Figure $6 \mathrm{~b}$ shows the perturbation meridional winds at the end of the simulation. Figure $6 \mathrm{~b}$ shows generally weak southward winds with a peak speed of $40 \mathrm{~m} \mathrm{~s}^{-1}$ between 120 and $130 \mathrm{~km}$ altitudes extending $200 \mathrm{~km}$ north and south from the model center. 


\section{Discussion}

\subsection{Comparison With Data}

Profiles of the perturbation zonal and meridional winds at the location and time of the ARIA wind measurements, approximately $225 \mathrm{~km}$ north of the model center (denoted by a solid triangle in Figures $6 \mathrm{a}$ and $6 \mathrm{~b}$ ) were added to the corresponding zonal and meridional STGCM wind profiles (in magnetic coordinates) respectively. Figure 7a shows the combined zonal model wind profile (solid line) and the observed zonal wind profile (dashed line), while Figure $7 \mathrm{~b}$ shows the combined meridional model wind profile (solid line) and the observed meridional wind profile (dashed line) for this time and location.

The observed wind profiles were inferred from photographs taken at different locations of a release of trimethal aluminate (TMA) (Larsen et al., submitted manuscript, 1994). Both observed wind profiles have been rotated into magnetic coordinates. The zonal winds (Figure 7a) are generally eastward, with a peak speed of $80 \mathrm{~m} \mathrm{~s}^{-1}$ at $150 \mathrm{~km}$, as might be expected as a result of ion drag with a southward electric field and a downward magnetic field. The meridional winds (Figure $7 \mathrm{~b}$ ) are generally southward with a peak speed of $140 \mathrm{~m} \mathrm{~s}^{-1}$ above $140 \mathrm{~km}$ and northward below. Between 110 and $135 \mathrm{~km}$, however, the observed winds exhibit rather unexpected behavior with a large southwestward jetlike feature of nearly $140 \mathrm{~m} \mathrm{~s}^{-1}$. A detailed description of the observed winds in presented by Larsen et al. (submitted manuscript, 1994).

A detailed comparison of our model zonal winds with the observed winds (Figure 7a) shows that above $135 \mathrm{~km}$ we predict the correct sense of the wind (eastward), the correct profile shape, and the correct altitude of the peak eastward winds (approximately 140-150 km). The peak magnitude of our model zonal winds $\left(175 \mathrm{~m} \mathrm{~s}^{-1}\right.$ ), however, is more than a factor of 2 faster than the peak observed winds $\left(80 \mathrm{~m} \mathrm{~s}^{-1}\right)$. Below $135 \mathrm{~km}$ the agreement is poorer as the model and observed winds are generally opposite in direction. The observations show a peak wind of $60 \mathrm{~m} \mathrm{~s}^{-1}$ westward at 120 $\mathrm{km}$, while the model winds at this altitude are $120 \mathrm{~m} \mathrm{~s}^{-1}$ eastward.

In comparing the model meridional wind with the observed meridional winds (Figure $7 \mathrm{~b}$ ), we see fair agreement in terms of general tendencies but poor agreement in terms of details. Generally, the model predicts the sense of the observed wind, southward above $110 \mathrm{~km}$ and northward below $110 \mathrm{~km}$, but the model neither compares well in magnitude nor reproduces the structure seen in the observations. This is especially true for the large southward jetlike wind excursion of $125 \mathrm{~m} \mathrm{~s}^{-1}$ between 110 and $120 \mathrm{~km}$.

In order to understand the causes of the differences between observed and model winds, we need to analyze the relative magnitudes of the sources of uncertainties in the model. The large difference in eastward winds predicted by the model and the observed winds above $135 \mathrm{~km}$ is most likely the result of an overprediction of the magnitude and spatial extent of the AMIE electric fields. AMIE electric field magnitudes show a strong inverse relationship to the conductivity pattern used [Kamide et al., 1981]. Anderson et al. [1995] showed that conductivities based on ARIA particle measurements of the diffuse aurora are at least twice as large as the climatological conductivities used in AMIE. Hence it is likely that locally the actual electric field in the aurora is
U-V AVERAGE WINDS (MAG)

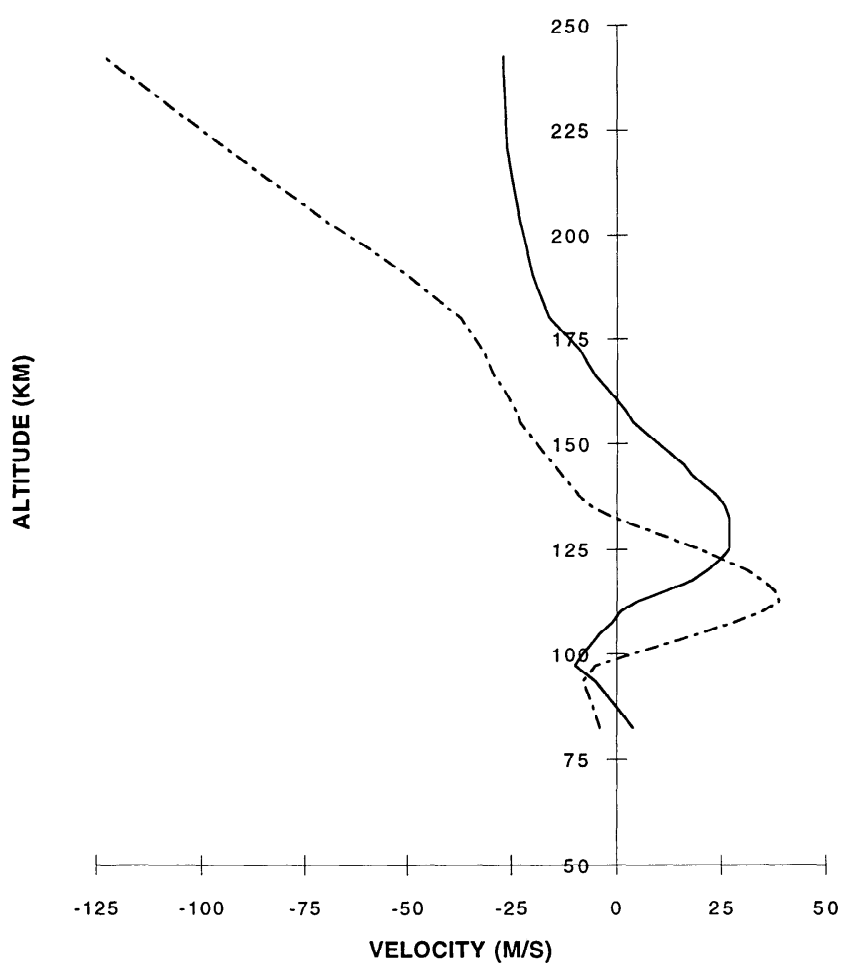

Figure 5. Background wind profiles determined from the time-average of 1200-1400 UT spectral global circulation model (STGCM) winds, spatially averaged around the ARIA rocket flight path. The zonal $V$ (east-west) wind profile (positive eastward) is shown as the solid line. The meridional $V$ (north-south) wind profile (positive northward) is shown as the dashed-dotted line. Winds have been rotated into magnetic coordinates.

much weaker than that specified by AMIE, resulting in slower zonal winds. A sensitivity test of the model with the electric field decreased by half reduces the peak perturbation wind by half. Figure $8 \mathrm{a}$ shows a comparison between the model zonal winds (solid line), the model zonal winds with electric field reduced by half (dashed-dotted-dotted line), and the observations (dashed line). Reducing the model electric field by half brings the model zonal winds into better agreement with the observed winds, but the peak model winds are still stronger than the observed winds by $50 \%$.

Another uncertainty is the accuracy of the STGCM zonal winds. Figure 8a also shows the relative strengths of the model perturbation zonal winds with the electric field reduced by half (solid gray line) and the STGCM zonal winds (dashed-dotted line). Between $135 \mathrm{~km}$ and $160 \mathrm{~km}$ the magnitude of the model and STGCM winds are roughly the same. (Above $160 \mathrm{~km}$ the STGCM winds decrease in strength.) Hence any significant uncertainty in the STGCM winds could adversely affect the combined wind profile. For example, the extent to which effects of auroral forcing have been included in the STGCM results could contribute to faster than observed zonal winds in the combined profile (model perturbation zonal winds and STGCM zonal winds).

Below $135 \mathrm{~km}$, Figure $8 \mathrm{a}$ shows that the perturbation zonal winds (with the electric field reduced by half) decrease 


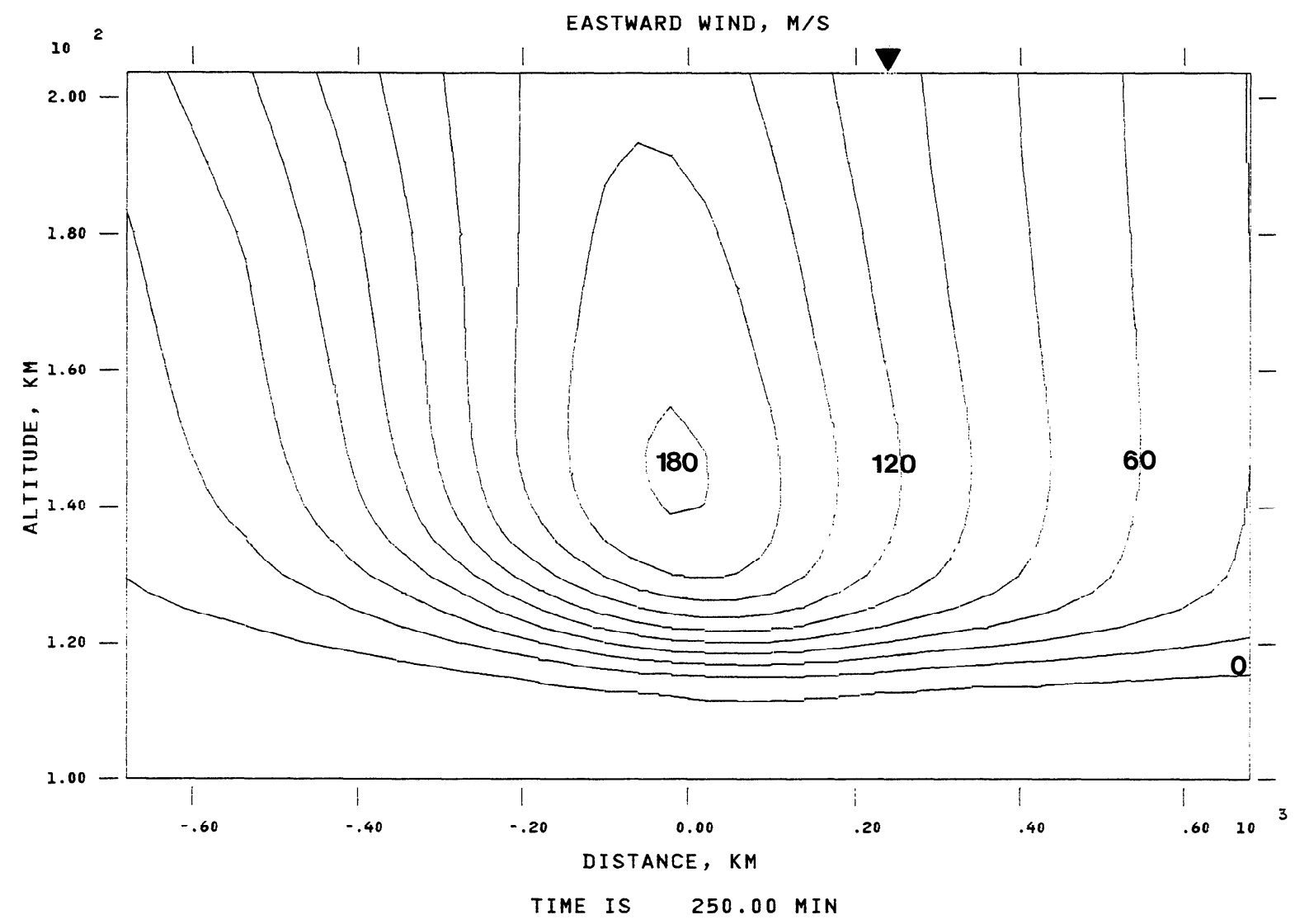

Figure 6a. Contour plot showing model perturbation zonal winds as a function of altitude and distance (in kilometers) from the model center (north is toward the right) at the end of the simulation. Contours are at $20 \mathrm{~m} \mathrm{~s}^{-1}$ intervals, positive eastward. The solid triangle denotes the location at which a slice through the model atmosphere was taken to compare with observations.

rapidly in strength from $60 \mathrm{~m} \mathrm{~s}^{-1}$ eastward at $135 \mathrm{~km}$ to near zero at $110 \mathrm{~km}$. This is because the increased collisions of neutrals on ions at the lower altitudes decreases the effectiveness of the ion drag forcing. The STGCM zonal winds also decrease in strength; they decrease from $50 \mathrm{~m} \mathrm{~s}^{-1}$ eastward at $135 \mathrm{~km}$ to zero at $105 \mathrm{~km}$. Below $105 \mathrm{~km}$ the winds become westward with a peak of $20 \mathrm{~m} \mathrm{~s}^{-1}$ at $100 \mathrm{~km}$. This lower altitude variation results from tides forced at the lower boundary in the STGCM. However, the observed winds show much larger variations than this below $135 \mathrm{~km}$. Since the perturbation zonal winds drop in speed below 135 $\mathrm{km}$ as expected, the differences between the model winds and the observed winds at these altitudes are most likely due to the winds predicted by the STGCM. The lack of agreement between predicted and observed winds suggests uncertainty in the representation of the effects of tides or upward propagating gravity waves near the STGCM's lower boundary.

To a lesser extent, uncertainties in the STGCM meridional winds, which blow across the aurora, could have an impact on the predicted zonal winds. For example, a sensitivity test of the model showed that a $50 \%$ increase in the cross-auroral wind reduces the perturbation winds by $20 \mathrm{~m} \mathrm{~s}^{-1}$. An additional source of uncertainty is the extent to which the electron density profiles and latitudinal scaling functions are accurate. However, we used local ground-based and rocket measurements to infer these quantities and believe them to be less uncertain than the electric field or the STGCM predictions.

Many of the factors that contribute to the uncertainties in the model zonal winds could also be reasons for the less than good agreement between the model and observed meridional winds. Figure $8 \mathrm{~b}$ shows a comparison between the model perturbation meridional winds (solid line), the model perturbation meridional winds with the electric field reduced by half (solid gray line), the STGCM meridional winds (dasheddotted line), and the observed winds (dashed line). Figure $8 \mathrm{~b}$ clearly shows that the STGCM winds are the principle contributor to the combined wind profile. Hence a large error in the STGCM meridional winds translates directly into commensurate error in the combined wind profile. For example, a poor representation of the effects of tides or upward propagating gravity waves near the STGCM's lower boundary would result in the combined profile not be being able to replicate the structure seen in the observations. Uncertainties in the magnitude and latitudinal variation of the electric field can also cause significant changes in the model perturbation meridional wind. This is because the perturbation meridional wind is sensitive to the magnitude and location of Joule heating which varies as the square of the electric field. Figure $8 \mathrm{~b}$ shows that a reduction of the electric field by half reduces the perturbation meridional wind (solid line) to a quarter of its original strength (solid 


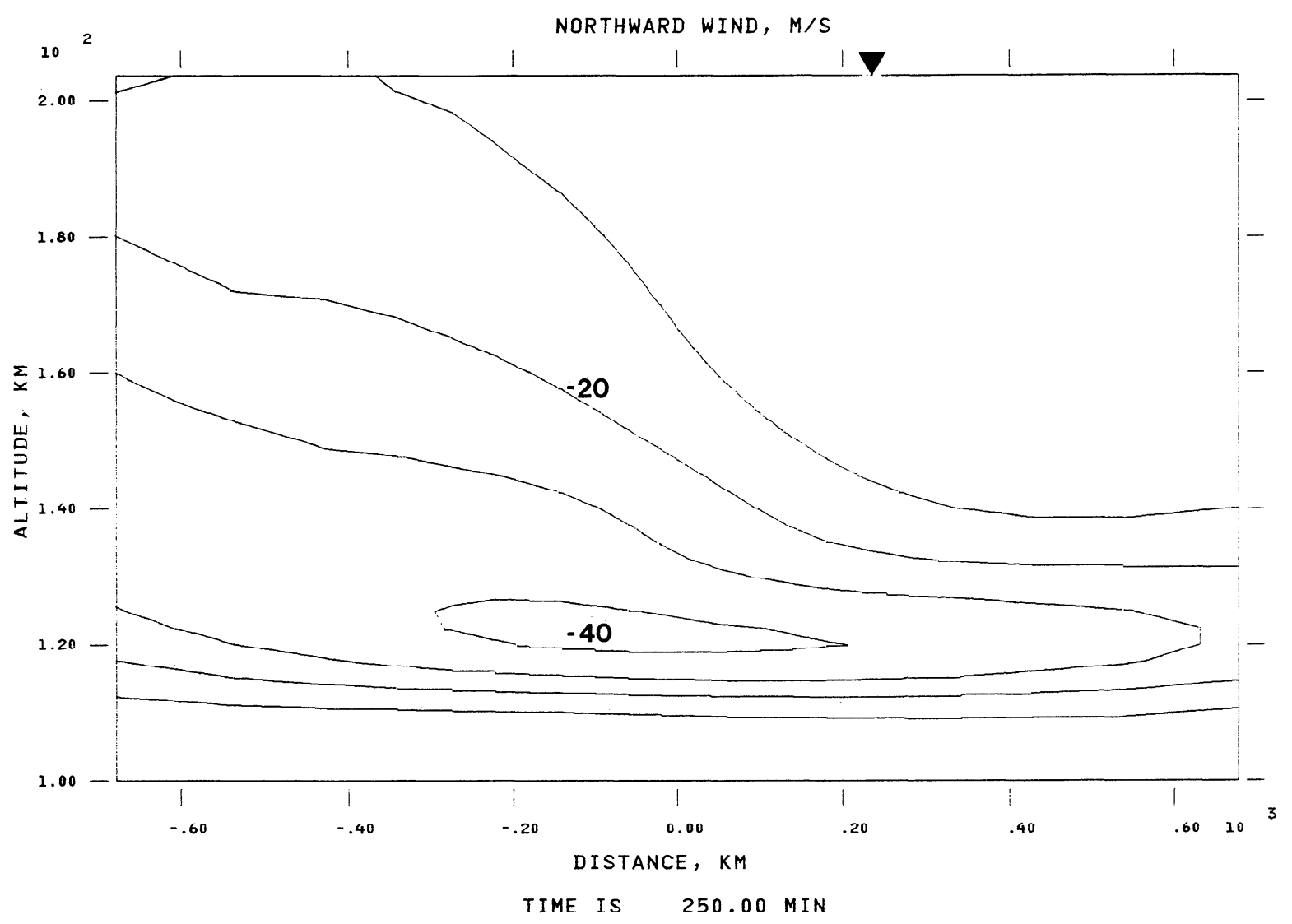

Figure 6b. Same as Figure 6a except for the meridional wind. Contours are at $10 \mathrm{~m} \mathrm{~s}^{-1}$ intervals, positive northward.

gray line). However, the perturbation meridional wind is already a minor contributor to the combined profile.

The "exotic" large southwestward jetlike feature in the observed winds between 110 and $135 \mathrm{~km}$ merits special comment. This feature is not captured at all by either component (zonal or meridional) of the model winds. This suggests that this feature could be the result of a phenomenon which originates outside the model domain and whose generation is specifically nonauroral and is thus not modeled. Phenomenon such as a breaking tide or gravity wave, or some type of boundary phenomena associated with the turbopause are possibilities. Another possibility is the acceleration of winds responding to the large-scale pressure gradients under conditions where the Hall drag has effectively reduced the Coriolis force, perhaps in combination with a breaking tide or gravity wave [Larsen and Walterscheid, 1995; Larsen et al., submitted manuscript, 1994]. Realistic simulation of this effect requires a much better vertical resolution than is possible with our current model.

Finally, the difference between the model winds and the observed winds could be the result of using a twodimensional model to simulate the inherently threedimensional thermosphere. For example, our two-dimensional model does not allow upwind conditions in the zonal direction to oppose the zonal accelerations generated in the main part of the aurora. This would lead to an overprediction of the zonal winds above $135 \mathrm{~km}$ in our model as compared to what might be expected in a three-dimensional model. As long as the upwind extent of the aurora is sufficiently great, this cffect is probably small compared to the other uncertainties discussed above.

\subsection{Comparison With Other Simulations}

The results shown here generally agree with the results of WL; both simulations exhibited a strong eastward wind jet with a broad latitudinal extent. Our simulation, however, exhibited smaller maximum wind speeds than those of WL. The peak winds of $175 \mathrm{~m} \mathrm{~s}^{-1}$ in our simulation are slower than the peak winds of $400 \mathrm{~m} \mathrm{~s}^{-1}$ for the soft spectra nominal width example from WL. This is not surprising as the two variables that determine the ion drag force (electron density and electric field) are smaller in our simulation. Although the incoming energy spectra and flux at the top of the atmosphere for the center of the aurora in our simulation (1.5-3.0 $\mathrm{keV}$ and $3-8.6 \mathrm{~mW} \mathrm{~m}^{-2}$, respectively) are similar to the soft spectra case in WL (a few kiloelectron volts and $7.6 \mathrm{~mW}$ $\mathrm{m}^{-2}$ ), the latitudinal variation in our simulation causes the enhanced electron densities to drop off quickly away from the auroral center, while for the WL example the enhanced electron densities were at their maximum value (e.g., scale factor equal to one) for approximately $90 \mathrm{~km}$ either side of the auroral center. Another factor contributing to a lower wind speed in our results compared with WL is the smaller magnitude and latitudinal extent of our model electric field. In the work by WL the electric field was a constant $-50 \mathrm{mV}$ $\mathrm{m}^{-1}$ across the entire model domain. However, in our simulation periods $1-3$ the electric field maximized at only $-21 \mathrm{mV} \mathrm{m}^{-1}$ (although this was over a fairly broad latitudi- 
TMA/WLM U-Comp (Mag)

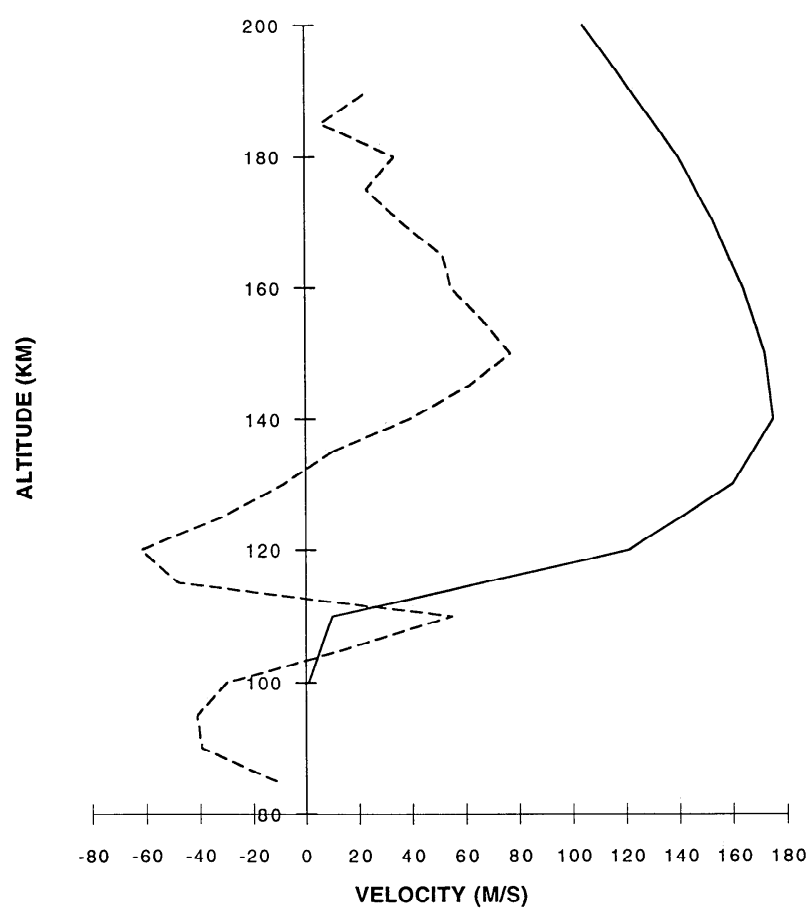

Figure 7a. Comparison of model (WLM) perturbation zonal (U-comp) winds (solid line) plus STGCM 1400 UT zonal (magnetic) winds and observed zonal winds based on a trimethal aluminate (TMA) release (dashed line) for a location approximately $225 \mathrm{~km}$ north of the model center. Winds are in unit of meters per second, positive eastward.

nal extent). During the final simulation period the electric field maximized at only $-34 \mathrm{mV} \mathrm{m}^{-1}$, decreased sharply away from the peak, and was shifted well out of the region of maximum electron density.

\section{Conclusions}

We have simulated the strong $E$ region zonal winds generated by ion drag in the postmidnight diffuse aurora based on measurements from the ARIA 1 rocket campaign. This is the first time that simulations using the time history of detailed specifications of the magnitude and latitudinal variation of the auroral forcing based on measurements have been compared to simultaneous wind measurements. Detailed airglow, spectral and latitudinal particle precipitation data, and direct electron density measurements were used to determine enhanced electron densities in the diffuse aurora. The electron densities, along with electric fields derived from magnetometer and DMSP satellite ion drift measurements, and large-scale cross-auroral winds specified by a thermospheric general circulation model, provided realistic inputs for the high-resolution nonhydrostatic dynamical model. The model predicted a strong core of eastward winds of $175 \mathrm{~m} \mathrm{~s}^{-1}$ at $E$ region heights.

A comparison of model winds with concurrent wind observations, $225 \mathrm{~km}$ north of the model center, showed modest agreement. Above $135 \mathrm{~km}$, the model predicted zonal winds with the correct sense, the correct profile shape, and the correct altitude of the peak wind. However, it overpredicted the magnitude of the eastward winds by more than a factor of 2 . The agreement between the model and observed meridional winds was not as good. The model predicted the general sense of the winds, southward above $110 \mathrm{~km}$ and northward below $110 \mathrm{~km}$, but failed to capture the magnitude or the structure seen in the observed winds.

Uncertainties in the magnitude and latitudinal extent of the model electric field due to an underestimate of conductivities used in the AMIE process and the winds specified by the STGCM are the most likely sources contributing to the differences between the model and observed winds. By comparison, the extent to which we have accurately specified the magnitude and variation of the enhanced electron densities is much less uncertain. The quantities were inferred from local ground-based and rocket-borne measurements. An additional uncertainty is the use of a twodimensional model to simulate the inherently threedimensional thermosphere.

Below $135 \mathrm{~km}$ the agreement between the model and observations was poor, as the predicted model winds (eastward at $120 \mathrm{~m} \mathrm{~s}^{-1}$ ) were opposite in direction to the observed winds (westward at $60 \mathrm{~m} \mathrm{~s}^{-1}$ ) between 110 and 120 $\mathrm{km}$. The large southwestward jetlike feature in the observed winds between 110 and $135 \mathrm{~km}$ is the result of an unmodeled phenomena such as a breaking tide or gravity wave, a turbopause boundary effect, Hall drag modification of the response to large-scale pressure gradients, or a combination of these phenomena.

The model winds in the present simulation were compared to the earlier simulations of WL. The comparison is favorable, although the winds in our simulations were considerably weaker than WL for particle precipitation of similar

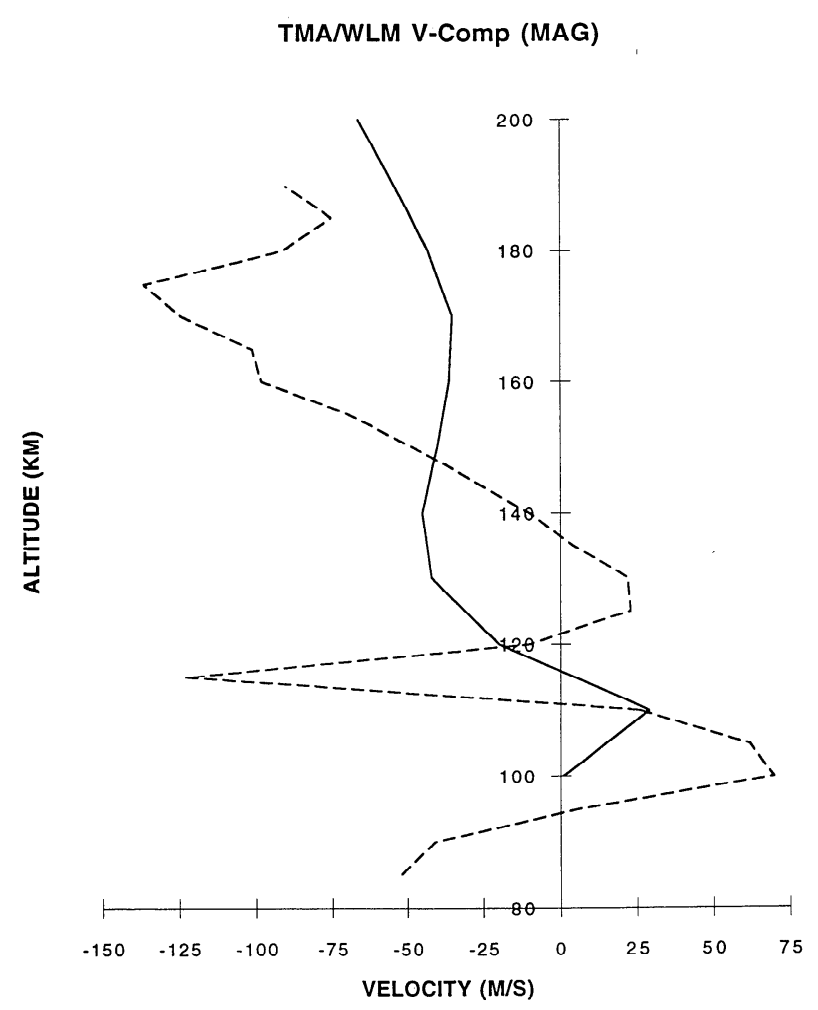

Figure 7b. Same as Figure $7 \mathrm{a}$ except for the meridional wind (positive, northward). 
characteristic energy and flux. The reason for the difference lies in the smaller latitudinal extent of our model diffuse aurora and the weaker fields in our simulation.

We have confirmed that ion densities in an active diffuse aurora support a strong response of the neutral atmosphere to the drag due to ions driven into motion by auroral electric fields. We note, however, that a detailed specification of the magnitude and latitudinal variation of the forcing associated with the diffusc aurora including the electric field, which can be reduced in strength due to increased conductivities in the diffuse aurora, is required to accurately predict the $E$ region thermospheric wind response. ARIA Kayser (a follow-on series of rocket flights) will make concurrent electron density and electric ficld measurements which will enable us to an even more detailed specification of the auroral forcing. Finally, we have shown that the "exotic" jetlike wind feature between 110 and $135 \mathrm{~km}$ is not aurorally forced with the possible exception of an enhancement of the Hall drag relative to the Coriolis force, which modifies the geostrophic balance with the large-scale pressure gradient. However, the details of the role of breaking tides or gravity waves, turbopause boundary effects, and Hall drag effects in determining this wind feature need further study.

Acknowledgments. The authors wish to acknowledge J. H. Hecht, P. C. Anderson, and P. R. Straus for their help in interpret-

\section{RELATIVE CONTRIBUTIONS of U-Comps (Mag)}

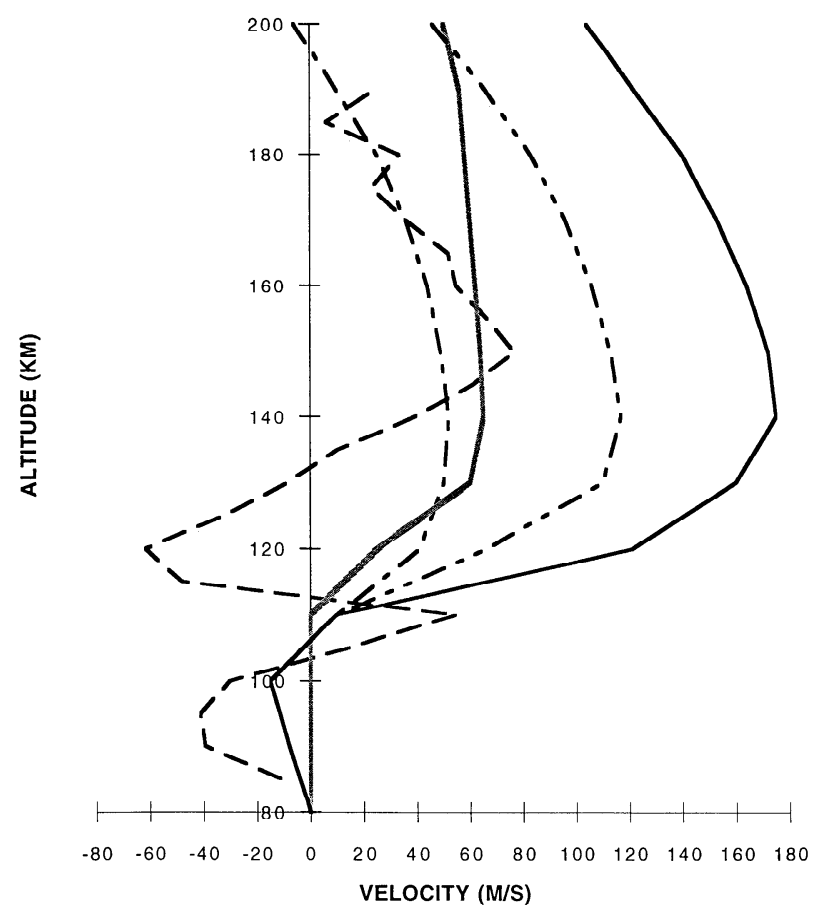

Figure 8a. Comparison of the combined model zonal winds (solid line), the combined model zonal winds with the electric field reduced by half (dashed-double-dotted line), the perturbation model zonal winds with the electric field reduced by half (solid gray line), and the STGCM zonal winds at 1400 UT (dashed-dotted line) with the observed zonal winds (dashed line) for a location $225 \mathrm{~km}$ north of the model center. Winds are in units of meters per second, positive castward.
RELATIVE CONTRIBUTIONS of V-Comps (MAG)

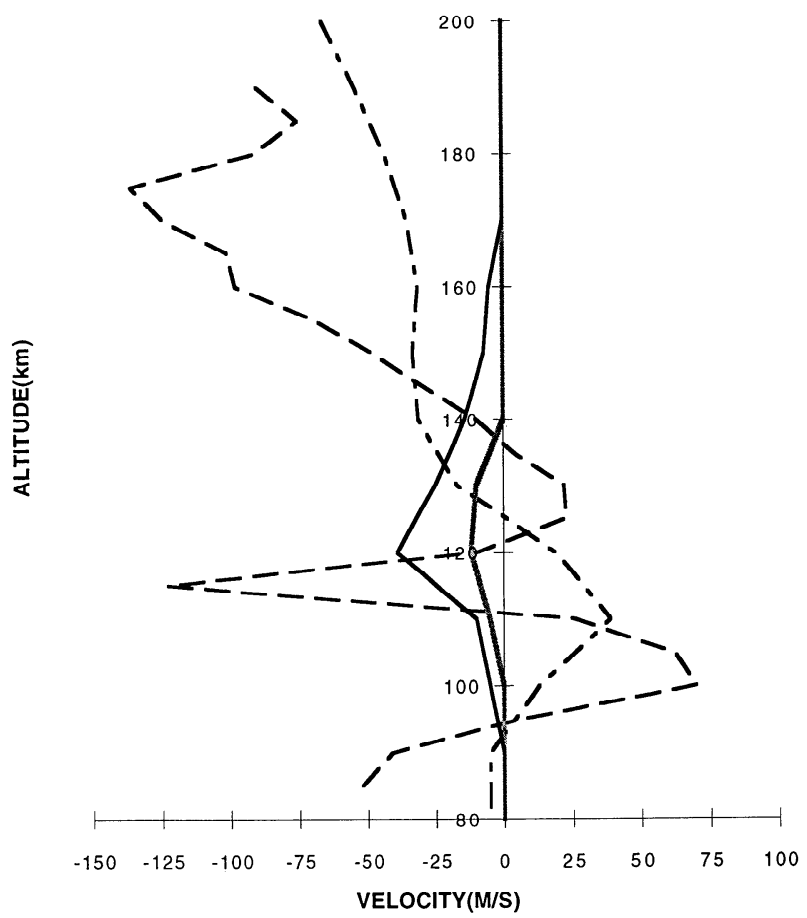

Figure 8b. Comparison of the perturbation model meridional winds (solid line), the perturbation model meridional winds with the electric field reduced by half (solid gray line), and the STGCM meridional winds (dashed-dotted line) with the observed meridional winds (dashed line) at the same time and location described in Figure 8a. Winds are in meters per second, positive northward.

ing the meridian scanning photometer data. Also, we would like to thank J. H. Hecht for running the Strickland code for us and A. S. Lozano for technical assistance. The work at the Aerospace Corporation was supported by the Aerospace Research Program of the Aerospace Corporation and NASA grants NSG-1632 and NAG55001; at Clemson University by Grants NAG5-632 and NAG5-5002; and at Southwest Research Institute by grant NAG5-5005.

The Editor thanks A. K. Smith and M. H. Rees for their assistance in evaluating this paper.

\section{References}

Akasofu, S.-I., A study of auroral displays photographed with the DMSP-2 satellite and from the Alaskan meridian chain of stations, J. Geophys. Res., 16, 617, 1974.

Anderson, P. C., et al., The ARIA 1 rocket campaign, J. Geophys. Res., in press, 1995

Chiu, Y. T., An improved phenomenological model of ionospheric density, J. Atmos. Terr. Phys., 37, 1563, 1975.

Daniell, R. E., Jr., and D. J. Strickland, Dependence of auroral middle UV emissions on the incident electron spectrum and neutral atmosphere, J. Geophys. Res., 91, 321, 1986.

Evans, D. S., N. C. Maynard, J. Trøim, T. Jacobsen, and A. Egeland, Auroral vector electric field and particle comparisons, 2, Electrodynamics of an arc, J. Geophys. Res., 82, 2235, 1977.

Forbes, J. M., and F. Vial, Monthly simulations of the solar semidiurnal tide in the mesosphere and lower thermosphere, $J$. Atmos. Terr. Phys., 51, 649, 1989.

Hays, P. B., R. A. Jones, and M. H. Rees, Auroral heating and the composition of the neutral atmosphere, Planet. Space Sci., 21, 559, 1973.

Hecht, J. H., A. B. Christensen, D. J. Strickland, and R. R. Meier, Deducing composition and incident electron spectra from ground- 
based auroral optical measurements: Variations in oxygen density, J. Geophys. Res., 94, 13,553, 1989.

Kamide, Y., A. D. Richmond, and S. Matsushita, Estimation of ionospheric electric fields, ionospheric currents, and field-aligned currents from ground magnetic records, J. Geophys. Res., 86, $801,1981$.

Killeen, T. L., R. W. Smith, P. B. Hays, N. W. Spencer, L. E. Wharton, and F. G. McCormac, Neutral winds in the high-latitude winter $F$ region: Coordinated observations from ground and space, Geophys. Res. Lett., 11, 311, 1984.

Killeen, T. L., et al., Mean neutral circulation in the winter polar $F$ region, J. Geophys. Res., 91, 1633, 1986.

Larsen, M. F., and I. S. Mikkelsen, The dynamic response of the high-latitude thermosphere and thermospheric storms, J. Geophys. Res., 88, 3158, 1983.

Larsen, M. F., and R. L. Walterscheid, Modified geostrophy in the thermosphere, I. Geophys. Res., in press, 1995.

Lindzen, R. S., Internal gravity waves in atmospheres with realistic dissipation and temperature, I, Mathematical development and propagation of waves into the thermosphere, Geophys. Astrophys. Fluid Dyn., 1, 303, 1970.

Lyons, L. R., and J. F. Fennell, Characteristics of auroral electron precipitation on the morningside, J. Geophys. Res., 91, 11,255, 1986.

Lyons, L. R., and R. L. Walterscheid, Generation of auroral omega bands by shear instability of the neutral winds, J. Geophys. Res., 90, 12,321, 1985.

Mikkelsen, I. S., and M. F. Larsen, A numerical modeling study of the interaction between the tides and the circulation forced by the high-latitude plasma convection, J. Geophys. Res., 96, 1203, 1991.

Perkey, D. J., and C. W. Kreitzberg, A time-dependent lateral boundary scheme for limited equation models, Mon. Weather Rev., 104, 744, 1976.

Richmond, A. D., and Y. Kamide, Mapping electrodynamic features of the high-latitude ionosphere from localized observations: Technique, J. Geophys. Res., 93, 5741, 1988.

Richmond, A. D., and S. Matsushita, Thermospheric response to a magnetic substorm, J. Geophys. Res., 80, 2839, 1975.

Richmond, A. D., et al., Mapping electrodynamic features of the high-latitude ionosphere from localized observations: Combined incoherent-scatter radar and magnetometer measurements for January 18-19, 1984, J. Geophys. Res., 93, 5760, 1988.
Roble, R. G., R. E. Dickinson, and E. C. Ridley, Global circulation and temperature structure of the thermosphere with high-latitude plasma convection, J. Geophys. Res., 87, 1599, 1982.

Roble, R. G., B. A. Emery, R. E. Dickinson, E. C. Ridley, T. L. Killeen, P. B. Hays, G. R. Carignan, and N. W. Spencer, Thermospheric circulation, temperature, and compositional structure of the southern hemisphere polar cap during OctoberNovember, 1981, J. Geophys. Res., 89, 9057, 1984.

St.-Maurice, J. P., and R. W. Shunk, Ion-neutral momentum coupling near discrete high-latitude ionospheric features, J. Geophys. Res., 86, 11,299, 1981.

Straus, J. M., and M. Schulz, Magnetospheric convection and upper atmospheric dynamics, J. Geophys. Res., 81, 5822, 1976.

Strickland, D. J., D. L. Book, T. P. Coffey, and J. A. Fedder, Transport equation techniques for the deposition of auroral electrons, J. Geophys. Res., 81, 2755, 1976.

Strickland, D. J., J. R. Jasperse, and J. A. Whalen, Dependence of auroral EUV emissions on the incident electron spectrum and neutral atmosphere, J. Geophys. Res., 88, 8051, 1983.

Walterscheid, R. L., and D. J. Boucher, A simple model of the transient response of the thermosphere and impulsive forcing, $J$. Atmos. Sci., 41, 1062, 1984.

Walterscheid, R. L., and L. R. Lyons, The neutral $E$ region zonal winds during intense postmidnight aurora: Response to observed particle fluxes, J. Geophys. Res., 94, 3703, 1989.

Walterscheid, R. L., L. R. Lyons, and K. E. Taylor, The perturbed neutral circulation in the vicinity of a symmetric stable auroral arc, J. Geophys. Res., 90, 12,235, 1985.

Whalen, J. A., A quantitative description of the spatial distribution and dynamics of the energy flux in the continuous aurora, $J$. Geophys. Res., 88, 7155, 1983.

D. G. Brinkman, A. B. Christensen, L. R. Lyons, and R. L. Walterscheid, Space and Environment Technology Center, The Aerospace Corporation, Los Angeles, CA 90009.

R. A. Frahm and J. R. Sharber, Department of Space Sciences, Southwest Research Institute, San Antonio, TX 78228.

M. F. Larsen, Department of Physics and Astronomy, Clemson University, Clemson, SC 29634.

(Received May 10, 1994; revised October 3, 1994; accepted October 27, 1994.) 